\title{
Effect of X-Word Grammar and Traditional Grammar Instruction on Grammatical Accuracy
}

\author{
Sue Livingston ${ }^{1}$, Andi Toce ${ }^{1}$, Cyndi Casey ${ }^{1}$, Fernando Montoya ${ }^{1}$, Bonny R. Hart ${ }^{2} \&$ Carmela O'Flaherty $^{3}$ \\ ${ }^{1}$ LaGuardia Community College, 31-10 Thomson Avenue, Long Island City, New York 11101, USA \\ 2924 West End Avenue, New York, New York 10025, USA \\ ${ }^{3}$ Bergen Community College, 400 Paramus Road, Paramus, New Jersey 07652, USA \\ Correspondence: Sue Livingston, Department of Education and Language Acquisition/Program for Deaf Adults, \\ LaGuardia Community College, Long Island City, New York 11101, USA. Tel: 917-841-6724. E-mail: \\ slivings@lagcc.cuny.edu
}

Received: December 29, 2017 Accepted: February 19, 2018 Online Published: February 20, 2018

doi: 10.5539/elt.v11n3p119 URL: http://doi.org/10.5539/elt.v11n3p119

\begin{abstract}
This study first briefly describes an instructional approach to teaching grammar known as X-Word Grammar and then compares its effectiveness in assisting students in achieving grammatical accuracy with traditionally taught grammar. Two groups of L2 pre-college students were taught using curricula and practice procedures in two different grammar texts over a three-month period of time for $20 \%$ of their class time. Essays written at three different times were analyzed for the correct and incorrect use of sentence patterns and verb constructs. Results demonstrated that improvement (writing with less error) was larger in both categories for the X-Word Grammar group and significant for two verb constructs as compared to the traditional grammar group, indicating that $\mathrm{X}$-Word Grammar students wrote more accurately in month three than they did in month one of the study when compared with students in the traditional grammar group. Possible reasons for these results are discussed in light of the differences in the two approaches and how these differences support the literature on ways of improving grammar instruction.
\end{abstract}

Keywords: accuracy, error analysis, grammar teaching, L2 writing, traditional grammar, X-word grammar

\section{Introduction}

Teaching second language (L2) writers to write with grammatical accuracy is an important component of L2 writing instruction. Accuracy has been defined in Wolfe-Quintero, Inagaki, and Kim (1998) as "the ability to be free from errors while using language in either writing or speech" (p. 33), and Ferris and Hedgcock (2014) describe error as "deviations from the grammatical rules of a language that violate the intuitions or expectations of literate adult native speakers of that language" (p. 283). Researchers have proved the positive effect of using corrective feedback on students' abilities to write with fewer errors, (Bitchener, Young, \& Cameron, 2005; Bitchner, 2008; Hartshorn et al., 2010; see Ferris \& Hedgcock, 2014 for a summary of recent findings), but research on the effectiveness of using direct instructional approaches in either L2 or EFL contexts, where students are explicitly taught how various grammatical elements work in linguistic contexts and then are expected to use them accurately, is lacking (G. Wang \& S. Wang, 2014). The few studies that have been done have yielded mixed results. Scheffler (2012) and Spada and Tomita (2010) report that explicit attention to grammatical form can result in improvements in free written production, but Frantzen (1995) and Macaro and Masterman (2006) contend that it leads to improvement on grammar tests but not to gains in accuracy in free written composition. This research tests the effectiveness of two different approaches to direct grammar instruction and asks which might show more gains in student accuracy in essay-writing contexts. It will first describe and exemplify a type of grammar instruction known as X-Word Grammar and contrast that with traditional grammar instruction. It will then compare the accuracy in the writing of a group of pre-college L2 students taught X-Word Grammar with the accuracy in the writing of a control group of students taught traditional grammar for sentence patterns and verb constructs over a three-month period of time. It is the first study to test the efficacy of using X-Word Grammar as an instructional approach to reduce error in the free writing of L2 writers. 


\subsection{Definitions}

\subsubsection{X-Word Grammar}

X-Word Grammar is a way of teaching grammar to L2 students that grew out of a graduate course taught by the linguist Robert L. Allen at Teachers College, Columbia University during the early 1970s. Allen's approach to teaching and analyzing English was called sector analysis and was based on two principles that differentiate it from other grammars: "It is construction oriented, not word-oriented; and it is a grammar of written English rather than of spoken English" (Allen, 1975, foreword). Sectors are positions in a sentence that can be filled with different construction-types, ranging from single words to trunks (simple sentences) to clauses, and essentially show how the different parts of a sentence relate to each other and build meaning to make larger structures (Kunz, 2006).

Allen's graduate students took sector analysis further and adapted it to meet the needs of classroom L2 teachers. Lessons were created that simplified the teaching of sectors and reorganized the teaching of the following 20 words called X-words. X-words occupy the sector closest to the subject and are seen below in Table 1 in their respective families.

Table 1. The $\mathrm{X}$-words in their families

\begin{tabular}{llllll}
\hline X-Word Families & X-Words & & & & \\
\hline The do family & do & does & did & & \\
The have family & have & has & had & & were \\
The be family & is & am & are & was & might \\
The modals & will & can & shall & may & \\
& would & could & should & must & \\
\hline
\end{tabular}

$\mathrm{X}$-words are the first auxiliaries of the English verb phrase (Kunz, 2006), and, most likely, get their name because of this. L2 teachers have been using X-Word Grammar for over 40 years, and there is now a Wiki http://xwordgrammar.pbworks.com established by Bonny R. Hart which has become a clearinghouse for all $\mathrm{X}$-word- related information and materials.

\subsubsection{Traditional Grammar}

Larsen-Freeman (2015) writes that grammar instruction today remains traditional with an emphasis on rule learning. In traditional grammar, the expectation is that rules learned and practiced in "discrete-item exercises... typically based on sentence completion, matching, true-false [or] multiple choice" (Ur, 2016, p. 115) will be used accurately in students' subsequent writing. Often, a class grammar book is used that is part of a "three-or four-volume grammar series, with each book targeting a predetermined list of grammar points deemed appropriate for learners at a specific proficiency level" (Folse, 2016, p. 63). Grammar lessons can follow the sequence established by the author of the book, which tends not to differ markedly from author to author, and these lessons are integrated with spoken communicative tasks to ensure that all language skills are used.

\subsection{X-Word Grammar, Traditional Grammar and Key Issues in Teaching Grammar}

In an effort to offer an understanding of how X-Word Grammar and traditional grammar differ, comparisons will be made between X-Word Grammar and traditional grammar based on what the literature highlights as issues in teaching grammar in general.

\subsubsection{Grammar Content}

Ellis (2006), drawing upon theory and research in L2 acquisition, presented eight controversial issues in grammar teaching. One is determining what grammatical structures should be taught. On one side, Krashen (1982) believes that teaching and learning grammar is possible only for simple rules, typically rules that are easy to teach and remember. On the other side is the stance of grammar textbook writers to "teach the whole of the grammar of the target language" (Ellis, 2006, pp. 87-88). Ellis understands the need to select structures to be taught due to limited amounts of teaching time but acknowledges the difficulty of knowing what to eliminate. "The problems of selection probably explain why grammatical syllabuses are so similar and have changed so little over the years; it is safer to follow what has been done before" (Ellis, p. 89). Typically, with respect to verb phrases, the order in grammar textbooks is "simple present, simple past, present progressive, future, past 
progressive" (Folse, 2016, pp. 69-70) and continuing on in the same or next-level text, to the irregular past, present perfect tenses, and, in more advanced texts, to the past perfect tense (p.72). In Azar and Hagen (2011), learning verb phrases (including learning the modal auxiliaries) requires 42 lessons (pp. v-vii).

In X-Word Grammar, there are only two tenses: past and present. These time concepts are built into the X-words and "carry all the time meaning of an English verb phrase" (Kunz, 2006a, p. 103). Past time X-words are did, had, was, were; present time X-words are do, does, have, has, am, is, are, can, shall, will, may and must. $\mathrm{X}$-words with dual time status are would, could, should and might. X-words also show number: if a subject is singular (does, is, was, has, am) or plural (do, are, were, have) or either singular or plural (will, would, can, could, shall, should, may, might, must). These time and number constructs are found in every sentence of English in the X-word. Even if X-words are not seen in a sentence, a do-family X-word is hiding in the main verb of the sentence where it continues to carry information about both time and number the way does hides in walks (symbolized as V/Xs) in She walks to work, do hides in walk (symbolized as V/Xo) in They walk to work, and did hides in walked (symbolized as V/XD) in We walked to work yesterday (Kunz, 2006a, pp. 29-32).

In addition, X-words "absolutely dictate the form of verbs that follow them" (Kunz, 2006a, p. 103). In Table 2, adapted from Kunz and Gluck (2000), we see how three main verb forms are "tied $100 \%$ without exception to the X-word families" (p. 19) that precede them. These are called X V matches.

Table 2. X-word families and main verb forms - X V Matches

\begin{tabular}{ll}
\hline X-Word Families & Main Verb Forms \\
\hline do, does, did & fly (base form) \\
can, could, will, would & \\
shall, should, may, might, must & \\
am, is, are, was, were & flying (_ing form) \\
have, has, had & flown (D, T, N form) \\
\hline
\end{tabular}

The XV matches in X-Word Grammar give us active, finite English verb phrases that show time and number in the X-word and aspect (how events are distributed in time and relate to different times) in the match ups above (Kunz, 2006b, p. 52).

Noguchi (1991) also claims that grammar content should be streamlined but adds that grammar teaching should show students the interlinked nature of language. He speaks directly to the need to better organize grammar teaching so that students can see relationships among the different elements of English grammar. Sloane (2009) demonstrates that in X-Word Grammar, since every trunk (T) or basic subject-predicate unit must have an $\mathrm{X}$-word, finding it and moving it to the front of the trunk will turn that trunk into a yes-no question (a-b). If the yes-no question doesn't look or sound right, it is not a trunk and most likely a fragment (c-d):

\section{$\mathrm{X}$}

(a) My students will write wonderful sentences.

$\mathrm{X}$

(b) Will my students write wonderful sentences? (p. 4)

$\mathrm{X}$

(c) When they are ready

$\mathrm{X}$

(d) Are when they are ready? *

Additionally, the slot between the moved X-word and the original X-word identifies the subject of the trunk:

$\mathrm{X}$

$\mathrm{X}$

My students 
Kunz (n.d., p. 2) shows how trunks can be attached to other trunks $(\mathrm{T},+\mathrm{T})$ by adding joiners such as and or a semi-colon (;) (e-f). The new structures in e-f require a comma and a joiner or a semi-colon because the construction type (trunk) on either side is the same, and both can be turned into yes-no questions (g). Without the joiner, with just a comma, the sentence is a run-on (h).

(e) It's very warm, and the sun is shining.

(f) It's very warm; the sun is shining

(g) Is it very warm? Is the sun shining?

(h) It is very warm, the sun is shining.

The sentences (e-h) refer to two different subjects, but in referring back to the same subject in a second (or third or fourth) predicate, there is no need to repeat the subject. This pattern is called a trunk with two parts $(\mathrm{T}=)$ and requires commas up until the last predicate as seen in (i) adapted from Kunz (n.d., p. 3):

(i) Jack gets up, eats breakfast, takes a shower and reads the newspapers.

There are places outside the trunk to attach additional information. Information placed outside the trunk can be in front of the trunk (FT) or at the end of the trunk (TE). Depending on emphasis, this information can shift from the front of the trunk to its end without changing meaning. Front shifters $(\mathrm{j}-1)$ require commas; end shifters $(\mathrm{m}-\mathrm{o})$ do not (Kunz, 2000, 80).

(j) When the sun rises, plants convert energy to food.

(k) If I had a little time, I'd explain it to you.

(1) After Friday's class, we can discuss this further.

(m) Plants convert energy to food when the sun rises.

(n) I'd explain it to you if I had a little time.

(o) We can discuss this further after Friday's class.

Learning the way sentences and parts of sentences join in X-Word Grammar offers students ways of managing their sentences through the correct use of punctuation (Sloane, 2009).

In Azar \& Hagen (2011), there is one chapter devoted to connecting ideas, but lessons on other aspects of sentence structure (using parallel verbs, time clauses, if clauses and since clauses) appear in chapters on time (p. v).

\subsubsection{Grammar Presentation and Practice}

Ur (2016) describes a model of language teaching known as Presentation-Practice-Production (PPP). The PPP model is associated with deductive, traditional and explicit grammar teaching methodologies wherein a new grammatical structure is first explained, practiced through focused activities and then produced by students in their own output which can include speaking tasks. At times, a short text is offered prior to the explanation of a specific structure that is enhanced to focus students' attention on the structure to be learned. Ur maintains that concentrating on accuracy-focused activities will not contribute to using the grammar point in subsequent free production because the practice tasks being asked of students are different from what students will need to do when creating their own contexts for writing. In addition, Fortune (as cited in Ellis, 2013) reported considerable variation in the way six popular grammar texts explained five grammatical structures noting oversimplification and misleading explanations while Lantolf (2007) criticized pedagogic rule descriptions as being unsystematic. Most grammar texts, however, rely on pedagogic descriptions (Ellis, 2016, p. 134).

In X-Word Grammar, while there are accuracy-focused activities, the emphasis is on, as much as possible, authentic readings which are used for students to see what English writers actually do (Kunz, 2000). Students are given tasks which call their attention to a particular grammatical feature in a reading by being asked to find it and label it through the use of grammar correction symbols (Kunz, 2000). (See Appendix A for a comparison of grammar correction symbols used in this study.) To assist students in remembering the correction symbols, they are used cumulatively in practice and editing activities. Because there are fewer rules in X-Word Grammar, and because they are described simply in a way that beginners can grasp, students learn to state the grammatical reasons for their answers to practice activities and are expected to gradually learn to grammatically analyze whatever it is that they read (Livingston, 2010). X-Word Grammar has been called discovery or inquiry-based instruction because it "leads students to move beyond rule memorization to discover patterns and discuss grammar in context" (Gluck, 2007, p. 46). 


\subsubsection{Corrective Feedback}

One issue concerning offering corrective feedback to L2 students is whether or not feedback should focus on "smaller, discrete categories of error... or simply indicate that there is a problem within a broad category" (Ferris \& Hedgcock, 2014, p. 287). As reported in Ferris and Hedgcock (2014), using fewer categories of error might better connect in-class instruction with later literacy activities, but runs the risk of confusing students and teachers due to distinctions that are hard to see. "Experienced teachers often disagree about whether an error should be classified as 'verb tense' or 'verb form'” (p. 287), so the broader category of verb might lead to fewer instructor errors. Ferris reports that writers of textbooks and editing handbooks are split on the issue of giving either narrow or broad feedback.

In X-Word Grammar, because grammar correction symbols are built into instruction and learned simultaneously as elements are being presented and practiced, they are narrow and specific to error types (Livingston, 2010).

As a summary of this section, differences between traditional grammar and X-Word Grammar are presented in Table 3.

Table 3. Differences between traditional grammar and X-word grammar on three key issues in L2 grammar teaching research

\begin{tabular}{|c|c|c|}
\hline $\begin{array}{l}\text { Key Issues in L2 Grammar } \\
\text { Teaching Research }\end{array}$ & Traditional Grammar & X-Word Grammar \\
\hline \multirow[t]{3}{*}{ Grammar Content } & $\begin{array}{l}\text { A wide range of forms based on } \\
\text { structural syllabi in leveled texts } \\
\text { targeted for specific proficiency } \\
\text { levels }\end{array}$ & $\begin{array}{l}\text { Substantially fewer forms that } \\
\text { are unleveled }\end{array}$ \\
\hline & $\begin{array}{l}\text { Related grammar forms dispersed in } \\
\text { various units }\end{array}$ & $\begin{array}{l}\text { Related grammar forms linked } \\
\text { together }\end{array}$ \\
\hline & $\begin{array}{l}\text { Lessons integrated with spoken } \\
\text { communicative tasks }\end{array}$ & $\begin{array}{l}\text { Lessons focus on written } \\
\text { language }\end{array}$ \\
\hline \multirow[t]{3}{*}{ Grammar Presentation and Practice } & Pedagogic rule descriptions & $\begin{array}{l}\text { Limited rules with simple } \\
\text { explanations }\end{array}$ \\
\hline & Presentation ... Practice ... Produce & $\begin{array}{l}\text { Discovery techniques including } \\
\text { labelling of structures taught } \\
\text { with correction symbols and use } \\
\text { of correction symbols to analyze } \\
\text { supplemental text }\end{array}$ \\
\hline & $\begin{array}{l}\text { Accuracy focused activities including } \\
\text { speaking activities }\end{array}$ & $\begin{array}{l}\text { Accuracy focused activities } \\
\text { based on writing only }\end{array}$ \\
\hline Corrective Feedback & $\begin{array}{l}\text { Feedback given on broad or narrow } \\
\text { categories of error with correction } \\
\text { symbols }\end{array}$ & $\begin{array}{l}\text { Feedback given on narrow } \\
\text { categories of error with } \\
\text { correction symbols }\end{array}$ \\
\hline
\end{tabular}

For this study, we compare the effectiveness of traditional grammar teaching with X-Word Grammar teaching and ask the following research questions:

Through which approach to teaching grammar - either through traditional grammar or X-Word Grammar -- do students show greater improvement in accuracy for sentence patterns and verb constructs over three months of 
course instruction?

Through which approach to teaching grammar - either through traditional grammar or X-Word Grammar - do students show greater improvement in accuracy for specific error types over three months of course instruction?

\section{Method}

\subsection{Participants and Research Context}

The 47 participants in this study were pre-college L2 students enrolled in the intermediate level of an intensive year-long English language immersion program at a community college in the eastern United States during the fall term (September through November) of 2014. Students placed into the program based on results of university-wide tests of reading and writing. Further placement into appropriate levels within the program was based on results of the Michigan English Language Test, a program-wide in-house writing test and teacher recommendation if the student was previously enrolled in the program. These measures of reading and writing proficiency provided a baseline of linguistic comparability between groups.

The curriculum for the 25-hour per week 12-week English language immersion program emphasizes the integration of academic reading and writing skills. For this investigation, students wrote 11 essays: seven were based on high-interest news articles which afforded students opportunities to think about different perspectives on issues raised in the articles; four were responses to two books required for the course. For all seven essays, students followed the standard prompt which is the same prompt used for the university-wide placement test for entering freshmen and exit from the college's developmental writing program:

Read the passage and write an essay responding to the ideas it presents. In your essay, be sure to summarize the passage in your own words, stating the author's most important ideas. Develop your essay by identifying one idea in the passage that you feel is especially significant, and explain its significance. Support your claims with evidence or examples drawn from what you have read, learned in school, and/or personally experienced.

For each of the seven articles, reading pedagogy included teachers guiding students through the texts by writing side annotations for each paragraph and discussing new concepts, vocabulary and idioms. After these guided readings, students had opportunities to share their opinions and insights about the issues raised in the readings as a class. Writing pedagogy, standardized for both classes, included analysis of essays that modeled the requirements of a passing college-entry essay and the creation of rough essay outlines.

Students wrote essays of at least 300 words, and these essays were revised three or four times until grammar errors were corrected for all essays except those used for this study. While attention to meaning-making was of primary importance in the revising process, grammatical issues were attended to in the process of clarifying meaning throughout the drafting process. Grammar correction symbols were used for what was taught, however, both teachers felt comfortable correcting more than what correction symbols could address.

\subsection{Procedures}

Two veteran English as a second language (ESL) teachers, both teaching over 10 years in the English language immersion program, agreed to participate in this study. One, an L2 speaker himself, agreed to teach grammar as he had always taught it, feeling comfortable following the structural syllabus in Azar and Hagan (2011). The other teacher, who taught using the X-Word Grammar approach for several years, agreed to teach grammar following the practices and procedures in Livingston (2010).

The 47 students were randomly placed in either the control traditional group $(\mathrm{N}=25)$ or the experimental $\mathrm{X}$-word group ( $\mathrm{N}=22)$ based on the odd or even status of the last digit of their student identification numbers. As a final check on group comparability, demographic survey data revealed that students had similar levels of education, similar numbers of years of studying English in classes and similar amounts of time using English outside of classes.

Teachers followed the same reading and writing pedagogies described, using the same articles and books, writing assignments and procedures, but, for $20 \%$ of class time each day (approximately one hour), differed in their approach to teaching grammar. To ensure that both teachers taught the same grammar points over the course of the term, a checklist was created to align grammar points taught. Both teachers remained faithful to the order of grammar points presented in their respective workbooks as well as to the respective practice activities for the majority of their grammar teaching time. For the control group, additional practice activities included supplemental workbook activities ("study the chart," fill in the blank, "complete the conversation"), and for the experimental group, additional practice activities included changing sentences in The New York Times to yes-no questions, analyzing texts using grammar correction symbols and doing sentence manipulation activities. Since 
teachers "are not mere conveyer belts delivering instruction in a lockstep manner" (Larsen-Freeman, 2015, p. 271), they were free to determine the amount of time they spent on teaching the grammar constructs targeted for analysis within the $20 \%$ of time allotted for grammar teaching. However, as an added check to ensure that the same grammar points were taught, grammar journals were kept which briefly described each of the lessons taught over the term.

First drafts of essays were collected at three data points -- September, October and November. The readings, which served as essay prompts, were different at each point (see Appendix B for a list of the readings) and chosen for interest level and writing accessibility as judged by prior use with different student groups. Following the same reading and writing pedagogies as during regular class time, teachers guided students through the readings and allowed time for discussion. Students outlined their essays in class and then composed them during their 90-minute computer lab time. They were allowed to use their outlines and dictionaries but not grammar or spell check. After each data collection point, essays were sent to a research assistant who substituted numbers for names at the top of each essay and created a master list of student names, their classes and respective numbers. This master list was sent to the research statistician and only copies of numbered essays were used by two raters and the researcher for error analysis.

\section{Data Analysis}

Two raters with experience teaching X-Word Grammar and the researcher, using 6 randomly chosen essays from the September data point, developed specific coding guidelines (see Appendix C) for marking error for the error types shown in Table 4. Traditional grammar terminology along with X-Word Grammar terminology (in parentheses) identify the error types targeted for analysis.

Table 4. Error types targeted for analysis

\begin{tabular}{ll}
\hline Verb Error Types & Sentence Pattern Error Types \\
\hline Tense (TIME--now/before, V/Xs, V/Xo, V/XD, XV) & Simple sentences (trunks--T) \\
Aspect/verb forms (XV matches) & Conjoined sentences (T,+T, T=) \\
Subject verb agreement (Number \#--SX, SV/Xs, SV/Xo, XV) & Sentences with subordinators (FT, TE) \\
\hline
\end{tabular}

Note. Now includes references to future time; Aspect refers to events distributed in time as used in base, progressive (_ _ ing) and participle (D, T, N) forms.

The error types selected were based on those structures the teachers taught. Both teachers started with verb constructs and either interspersed or followed with teaching sentence patterns. These particular types of error also give L2 writers the most difficulty (Bitchner \& Ferris, 2012, p. 97).

There were several passes at developing the coding guidelines to mark error, but, through discussion and continued revision, a multi-page chart was created which included examples of errors in context, the error type that was being exemplified and reasons for categorizing the example as a certain error type. General directions were listed upfront to remind raters how to approach the task of coding. Each student's essay was duplicated so that one copy could be marked up for verb errors and one could be marked up for errors in sentence patterns.

The first 300 words of each essay were analyzed for errors using the guidelines and codes in Appendix C. It was decided that the percent of error for error types would not change much after 300 words. If a student's intent was not understandable, the sentence was not used, and the number of words in that sentence was counted and that number of words was then added after the $300^{\text {th }}$ word for further analysis. Mostly all students wrote over 300 words. Tally sheets were created and the number of right instances of a construct or pattern in an essay was tabulated along with the number of wrong instances of that same construct or pattern. The total number of attempts of a particular construct or pattern for each essay was then calculated and the number of wrong instances or errors was calculated as a percent of the number of total attempts for that construct or pattern. This ratio method of calculating accuracy for error types is considered more valid than other measures of accuracy in student writing (Wolfe-Quintero et al., 1998).

There were two checks on rater reliability. First, the researcher and the two raters who created the coding guidelines used them to rate six randomly selected essays from the October data set independently. Data collected from the researcher was compared against the aggregate responses of the two raters. A total of 68 sentence patterns and 280 verb constructs were used from the 6 essays. Each instance was marked as either an 
error or correct by each rater. Tables 5 and 6 summarize the researcher's and raters' scoring and indicate the number of instances where there was a disagreement.

Table 5. Inter-rater reliability data for sentence patterns

\begin{tabular}{lll}
\hline & Rater Error & Rater Correct \\
\hline Researcher Error & 19 & 2 \\
Researcher Correct & 8 & 46 \\
\hline
\end{tabular}

The data for sentence patterns show a 95.6\% level of agreement (65 out of 68 instances). The Cohen's kappa coefficient $(\kappa)$ is 0.895 which is an indicator of a very strong agreement.

Table 6. Inter-rater reliability data for verb constructs

\begin{tabular}{lll}
\hline & Rater Error & Rater Correct \\
\hline Researcher Error & 12 & 3 \\
Researcher Correct & 8 & 257 \\
\hline
\end{tabular}

The data for verb constructs show a $96.1 \%$ agreement ( 269 out of 280 instances) with $\kappa=0.883$, also indicating strong inter-rater reliability.

While rater variation was low, there were several discussions about what to consider an error. In an attempt to reduce possible subsequent rater variation, the discussion and rating sessions served to calibrate the researcher, who had been coding error using X-Word Grammar correction codes for over 10 years, to rate the remaining essays. As a check on intra-rater reliability, ten essays randomly selected were rated twice by the researcher six months apart (March 2015 and September 2015). Tables 7 and 8 summarize the data.

Table 7. Intra-rater reliability data for sentence patterns

\begin{tabular}{lll}
\hline & September Error & September Correct \\
\hline March Error & 71 & 4 \\
March Correct & 6 & 99 \\
\hline
\end{tabular}

The data for sentence patterns show a $94.4 \%$ agreement $(170$ out of 180 instances) with $\kappa=0.885$, which is considered strong.

Table 8. Intra-rater reliability data for verb constructs

\begin{tabular}{lll}
\hline & September Error & September Correct \\
\hline March Error & 60 & 2 \\
March Correct & 3 & 670 \\
\hline
\end{tabular}

The data for verb constructs show a $99.3 \%$ agreement ( 730 out of 735 instances) with $\kappa=0.995$, which is considered very strong.

\section{Results}

\subsection{Analysis of Total Error}

The first research question for this study was:

Through which approach to teaching grammar -- either through traditional grammar or X-Word Grammar -- do students show greater improvement in accuracy for sentence patterns and verb constructs over three months of 
course instruction?

The error percentage was calculated for both sentence patterns and verb constructs in September and November and results are summarized in Table 9 and Figure 1 for sentence patterns and Table 10 and Figure 2 for verb constructs.

Table 9. Combined sentence pattern error rate comparison

\begin{tabular}{lllllll}
\hline & $\begin{array}{l}\text { September } \\
\text { Errors }\end{array}$ & $\begin{array}{l}\text { September } \\
\text { Attempts }\end{array}$ & $\begin{array}{l}\text { September } \\
\text { Percentage }\end{array}$ & $\begin{array}{l}\text { November } \\
\text { Errors }\end{array}$ & $\begin{array}{l}\text { November } \\
\text { Attempts }\end{array}$ & $\begin{array}{l}\text { November } \\
\text { Percentage }\end{array}$ \\
\hline Traditional Grammar & 161 & 312 & $51.60 \%$ & 172 & 390 & $44.10 \%$ \\
X-Word Grammar & 197 & 329 & $59.88 \%$ & 187 & 411 & $45.50 \%$ \\
\hline
\end{tabular}

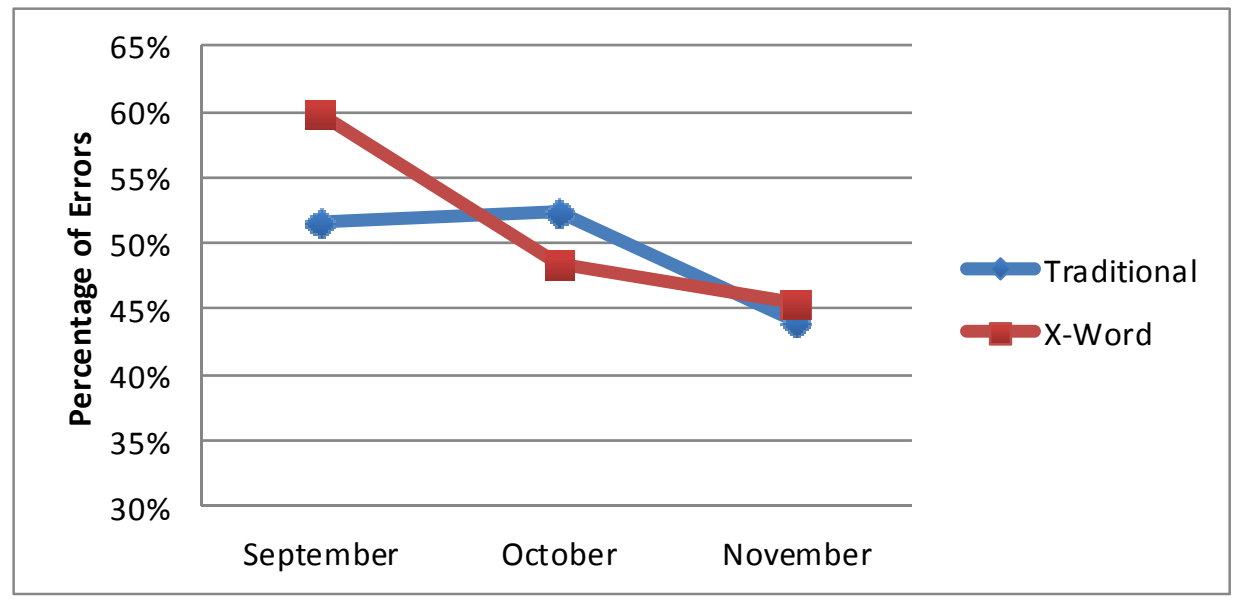

Figure 1. Combined sentence pattern error rate comparison

Table 10. Combined verb error rate comparison

\begin{tabular}{lllllll}
\hline & $\begin{array}{l}\text { September } \\
\text { Errors }\end{array}$ & $\begin{array}{l}\text { September } \\
\text { Attempts }\end{array}$ & $\begin{array}{l}\text { September } \\
\text { Percentage }\end{array}$ & $\begin{array}{l}\text { November } \\
\text { Errors }\end{array}$ & $\begin{array}{l}\text { November } \\
\text { Attempts }\end{array}$ & $\begin{array}{l}\text { November } \\
\text { Percentage }\end{array}$ \\
\hline Traditional Grammar & 164 & 1209 & $13.56 \%$ & 203 & 1510 & $13.44 \%$ \\
X-Word Grammar & 169 & 1189 & $14.21 \%$ & 139 & 1556 & $8.93 \%$ \\
\hline
\end{tabular}

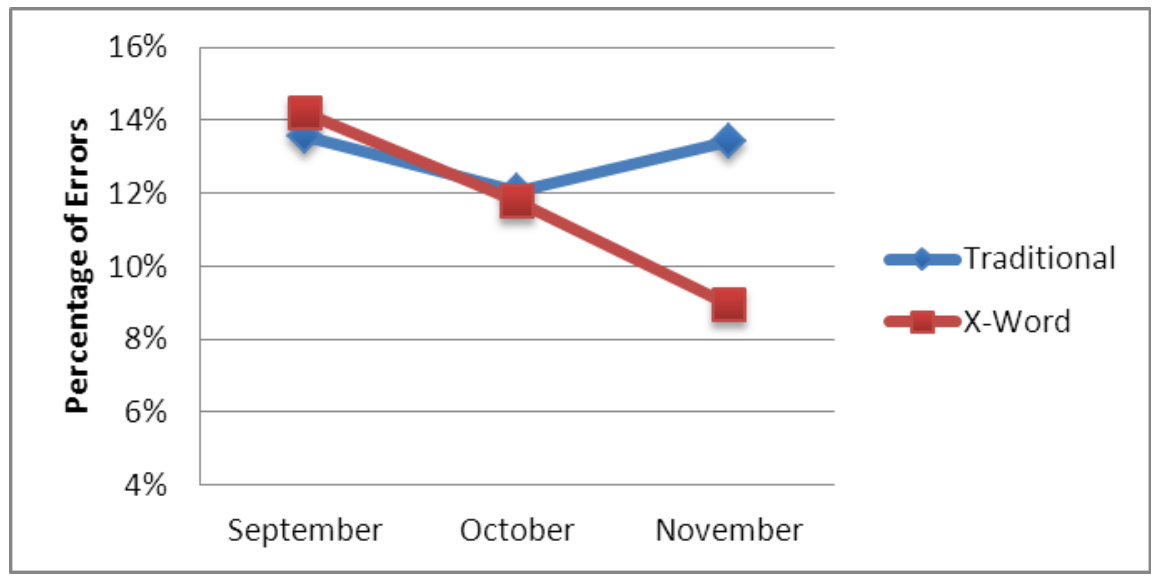

Figure 2. Combined verb error rate comparison 
In order to assess the effects of using each teaching method, student improvement rate was calculated as the difference between the September error percentage and the November error percentage. In both categories, improvement over the September - November period was larger for the X-Word Grammar group as compared to the traditional grammar group. For sentence patterns, the error rate improved by 7.5 percentage points (from $51.60 \%$ to $41.10 \%$ ) for the traditional grammar group. The X-Word Grammar group had an improvement of 14.38 percentage points (from $59.88 \%$ to $45.50 \%$ ). Similarly, the X-Word Grammar group performed better in the verb construct category. The improvement for the traditional grammar group was 0.12 percentage points $(13.56 \%$ to $13.44 \%)$ as compared to the X-Word Grammar group improvement of 5.25 percentage points $(14.21 \%$ to $8.93 \%)$. To determine significance, a t-test for both sentence patterns and verb constructs was performed. The p-value for the sentence patterns comparison is 0.244 which is not statistically significant. This may be due in part to the limited amount of sentence pattern data available. For the verb construct category, the t-test shows that the p-value is 0.056 which is borderline significant. In this category, the evidence is strong enough to believe that X-Word Grammar allowed students to show greater gain.

\subsection{Analysis of Error Types}

Our second research question asked through which approach to instruction students would show greater improvement for specific error types for sentence patterns and verb constructs over a three-month period of time.

As stated in sub-section 4.1, improvement is defined as the difference between the September error percentage and the November error percentage. In both categories of comparison (sentence pattern error types and verb construct error types), a larger improvement in percentage points indicates that students used that grammar construct more accurately in November than they did in September. The results are summarized in Figure 3 for sentence pattern error types and Figure 4 for verb construct error types.

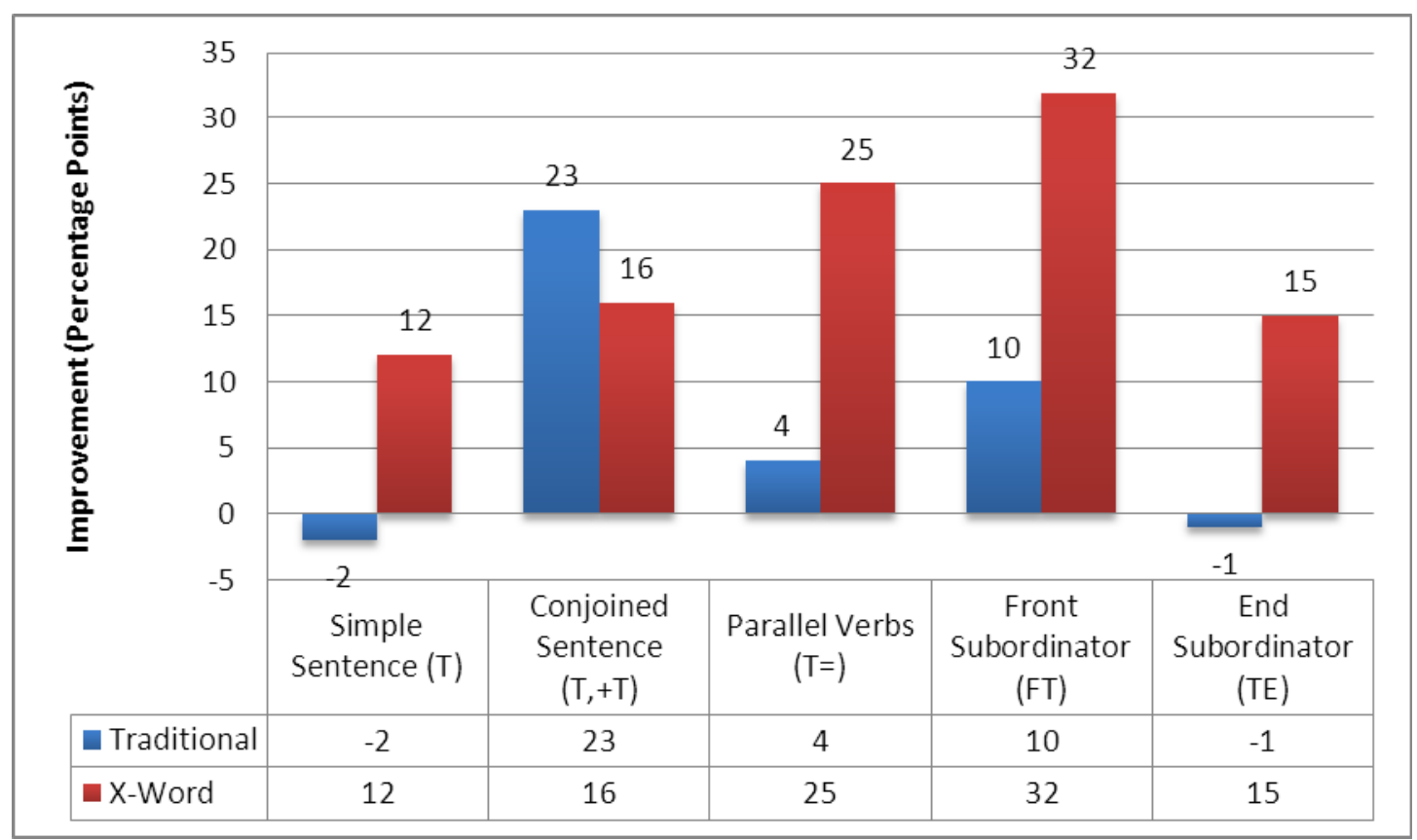

Figure 3. Improvement comparison for sentence pattern error types from September to November

In all categories of sentence pattern error type except for one (conjoined sentences, $\mathrm{T},+\mathrm{T}$ ), improvement was larger for the X-Word Grammar group as compared to the traditional grammar group. Statistical significance cannot be established in the individual categories largely as a consequence of the limited availability of data for sentence patterns. 


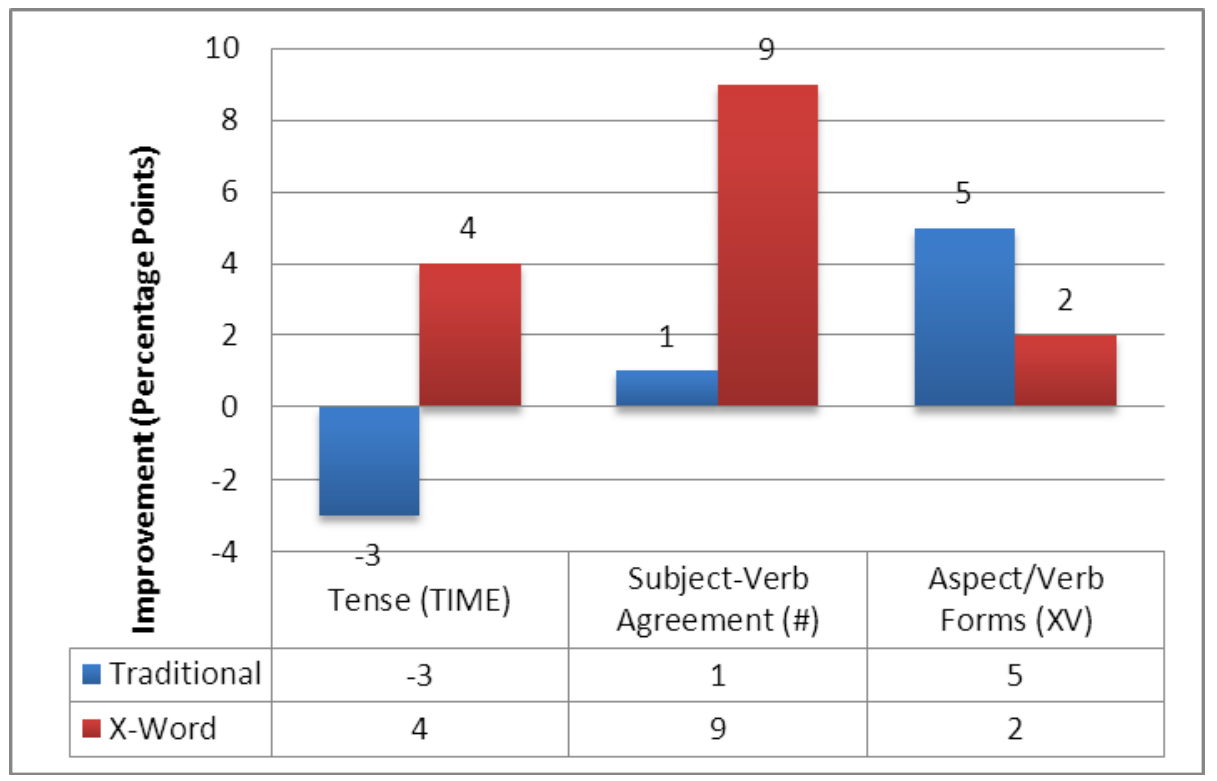

Figure 4. Improvement comparison for verb construct error types from September to November

Verb constructs of tense (TIME) and subject-verb agreement (Number \#) showed larger improvement for the $\mathrm{X}$-Word Grammar group. Statistical comparisons for individual verb constructs indicate that the observed differences are significant for subject verb agreement $(p=.018)$, borderline significant for tense $(p=.091)$, and not significant for aspect and verb forms $(\mathrm{p}=0.134)$.

\section{Discussion}

Two approaches to teaching grammar, X-Word Grammar and traditional grammar, were compared to see which better assisted students in using sentence patterns and verb constructs more accurately in their required course essays over three months of course instruction. While improvement in the use of both sentence patterns and verb constructs was larger for the $\mathrm{X}$-word group, improvement in the use of verb constructs showed significance. The question to be discussed, then, is what is it about the differences between X-Word Grammar and traditional grammar that merit these findings? Table 3 outlines the differences between the two approaches and will be further analyzed here to shed light on how the findings of this study might add to the discussion of what to consider when teaching students to write with less error.

\subsection{Grammar Content}

Table 3 indicates that X-Word Grammar works with fewer forms than traditional grammar. With respect to tense (TIME), concepts of present time (now time, including future time) and past time (before time) are built into each X-word and reflect all the time meaning in any English sentence. There is no need to devote concentrated time to show how each of these time constructs are expressed in progressive and perfect aspects which most traditional grammar texts do. This reduces the number of discrete grammar points needed to be taught for understanding concepts of tense. In addition, in X-Word Grammar, the construct of subject-verb agreement (number \#) is built into the $\mathrm{X}$-words in any English sentence. For the traditional grammar group, for this construct, students were taught changes in the spelling of verbs in simple present and present progressive tenses when subjects were either singular or plural. It is possible that the significant improvement for verb constructs of tense and number in this study was due to the efficiency of the X-Word Grammar system to present these constructs in simpler and more inclusive ways. Students learn that X-words have "two faces" because they simultaneously show tense and number, and they see these constructs in all sentences.

Table 3 also notes that X-Word Grammar links together related grammar constructions. In X-Word Grammar, sentences with subordinators (FT and TE) are taught as ways of connecting phrases related to time, reason, contrast, condition and location at the beginning and ending of sentences. They are taught in the same unit with sentences that are conjoined with coordinating conjunctions, with constructions that insert phrases and clauses within sentences and with words or phrases that link sentences across sentence boundaries. For the traditional grammar group, subordinate clauses were taught from different chapters of the class text where they were 
embedded in the teaching of tense for time and if-clauses and in the teaching of the present perfect for since clauses. They were taught primarily as a way of teaching tense and aspect constructs but not as a way to see how subordination works in general and how it is different from other ways to combine sentence parts. While improvement using these particular patterns was not significant, increased correct use of them by members of the $\mathrm{X}$-word group might be attributable to the fact that for learning subordination, accuracy improves when students are given a broader view of all sentence patterns to compare and contrast as opposed to learning subordination for purposes of teaching time constructs separate from other sentence patterns.

There were two error types that could not be submitted for the data analysis for this research: connectives or transitions (LT) (She was a great student athlete. In addition, she was on the honor roll); and adjective phrases (TI) (John Fitzgerald Kennedy, the youngest man ever elected president, was shot to death on November 22, 1963). While both patterns were included in the initial design of this study, the teacher of the traditional grammar group did not have enough time to teach them while the teacher of X-Word Grammar did. This might be explained by the way X-Word Grammar packages more grammar information into the teaching of verbs and by the way it shows relatedness among sentence structures, thereby enabling the teacher of the $\mathrm{X}$-word class to move more quickly through the grammar curriculum for this study.

\subsection{Grammar Presentation and Practice}

Table 3 shows that X-Word Grammar and traditional grammar differ with respect to grammar presentation and practice. While both approaches expect students to pay attention to or notice specific grammatical forms during presentation, X-Word Grammar might better bridge the gap between what is presented and what is practiced. In the X-Word Grammar text, students used the grammar correction symbols for editing to label the particular grammatical element being studied in the practice text exercises and, at times, in supplemental readings. In the traditional grammar text, there was no use of grammar correction symbols on practice text exercises. Researchers have written about the lack of connectedness between in-class grammar instruction and other reading and writing that students must do (Ferris, 2016; Ellis, 2016). It is perhaps X-Word Grammar's way of connecting grammar knowledge through the active use of correction symbols on practice exercises with their use in other supplemental texts that might have added to the reason for the increased reduction in student error over time in their essays. It is possible that the grammatical labelling of text made learning these patterns more interactive and thereby more discernible for future use.

In addition, with respect to practice time, recycling and review of grammar constructs for time and number were more easily accomplished through X-Word Grammar as those constructs are embedded and carried along with the X-words whether they are seen or hidden in all sentences. Accuracy, then, might depend on the recycling and review of constructs in a myriad of differing contexts (Hinkel, 2015).

\subsection{Corrective Feedback}

Larsen-Freeman (2015) questions whether or not it is helpful to view grammar as a rule-governed system. She acknowledges that while rules can describe a grammatical system, she asks if rules are what are being acquired in learning grammar or rather if students learn patterns from exemplars and if it is these exemplars that stay with students. It might be that students need ways of making language exemplars more salient. Table 3 shows that $\mathrm{X}$-Word Grammar and traditional grammar code grammar error differently and Appendix A exemplifies the differences in the correction symbols used for both groups of students. It can be seen that verb construct and sentence pattern correction symbols were more refined, directive and numerous for the $\mathrm{X}$-word group. What the higher improvement percentage for accuracy over time for the X-word group might point to is the need to call students' attention to past exemplars by correcting student writing in more directive ways which guide them to remember what specific corrections need to be made.

\section{Conclusion}

In an effort to assist L2 students to improve the accuracy of their writing, the effectiveness of two different approaches to grammar instruction - X-Word Grammar and traditional grammar -- was compared for sentence patterns and verb constructs. In both categories, the combined improvement over the September to November period was larger for the X-Word Grammar group as compared to the traditional grammar group with significance demonstrated for the $\mathrm{X}$-word group in their use of two verb constructs.

Possible reasons for the overall effectiveness of X-Word Grammar in this study were discussed with reference to well-known issues in the teaching of grammar documented in Ellis (2006, 2016), Ferris and Hedgcock (2014), Hinkle (2015), Noguchi (1991) and Ur (2016). Reasons discussed speak to the need to simplify the teaching of grammar, to systematize the teaching of structures, to connect grammar knowledge with grammar practice more 
directly through the use of more specific grammar correction symbols and to recycle and review constructs taught.

Polio and Shea (2014) acknowledge the difficulty of identifying accuracy development within a single semester and suggest that faculty and administrators consider giving students more time - perhaps multiple semesters -- to work on their language before evaluating accuracy. The greater improvement in accuracy over the three months of this experiment for the X-Word Grammar students points toward even possibly greater gain with continued instruction in X-Word Grammar and postponed evaluation.

It is hoped that this study contributes to the L2 literature by offering teachers an alternative way to conceptualize English grammar and its teaching. Citing Borg (2010) and Pedrazzini and Nava (2012), Larsen-Freeman (2015) maintains that "the most important contribution of research to practice is to challenge teachers to think differently, to experiment with new practices, and to help them make the tacit explicit by cultivating new ways of talking about their practice" (p. 274). This study is offered as a way to begin this discussion.

\section{Acknowledgments}

The authors thank Tamara Kirson and Ann Chen for their initial help with the design of this study.

\section{References}

Allen, R. L., Pompian, R., \& Allen, D. (1975). Working sentences. New York, NY: Thomas Y. Crowell Company.

Azar, B. S., \& Hagen, S.A. (2011). Fundamentals of English grammar (4th ed.). White Plains, NY: Pearson.

Bitchener, J. (2008). Evidence in support of written corrective feedback. Journal of Second Language Writing, 17, 102-118. https://doi.org/10.1016/j.jslw.2007.11.004

Bitchener, J., \& Ferris, D. (2012). Written corrective feedback in second language acquisition and writing. New York, NY: Routledge.

Bitchener, J., Young, S., \& Cameron, D. (2005). The effectiveness of different types of corrective feedback on ESL student writing. Journal of Second Language Writing, 14, 191-205. https://doi.org/10.1016/j.jslw.2005.08.001

Ellis, R. (2006). Current issues in the teaching of grammar: An SLA perspective. TESOL Quarterly, 40, 83-107. https://doi.org/10.2307/40264512

Ellis, R. (2016). Grammar teaching as consciousness raising. In E. Hinkel (Ed.), Teaching English grammar to speakers of other languages (pp. 128-148). New York: Routledge.

Ferris, D. (2016). Promoting grammar and language development in the writing class: Why, what, how, and when. In E. Hinkel (Ed.). Teaching English grammar to speakers of other languages (pp. 222-239). New York: Routledge.

Ferris, D., \& Hedgcock, J. S. (2014). Teaching L2 composition: Purpose, process and practice (3rd ed.). New York, NY: Routledge.

Folse, K.S. (2016). Grammar in student books vs. grammar that students need: Which grammar to include, which grammar to omit. In E. Hinkel (Ed.), Teaching English grammar to speakers of other languages (pp. 63-83). New York: Routledge.

Frantzen, D. (1995). The effects of grammar supplementation on written accuracy in an intermediate Spanish $\begin{array}{lllll}\text { content } \quad \text { course. } & \text { Modern }\end{array}$ https://doi.org/10.1111/j.1540-4781.1995.tb01108.x

Gluck, L. (2007). Inquiry-based grammar instruction. In Transit: The LaGuardia Journal on Teaching and Learning, 2, 43-47. Retrieved from http://xwordgrammar.pbworks.com

Harthshorn, K. J., Evans, N. W., Merrill, P. F., Sudweeks, R. R., Strong-Krause, D., \& Anderson, N. J. (2010). Effects of dynamic corrective feedback on ESL writing accuracy. TESOL Quarterly, 44, 84-109. https://doi.org/10.5054/tq.2010.2013781

Hinkel, E. (2015). Effective curriculum for teaching L2 writing: Principles and techniques. New York: Routledge.

Krashen, S. (1982). Principles and practices in second language acquisition. Oxford, England: Pergamon.

Kunz, L. (n.d.). Using rods to teach X-Word Grammar. Unpublished manuscript. Retrieved from http://xwordgrammar.pbworks.com 
Kunz, L. (2006a). X-Word Grammar for ESOL teachers. Unpublished manuscript. Retrieved from http://xwordgrammar.pbworks.com

Kunz, L. (2006b). X-Word Grammar for public school teachers. Unpublished manuscript. Retrieved from http://xwordgrammar.pbworks.com

Kunz, L. (2000). X-Word intermediate: A grammar editing book (Rev. ed.) Unpublished manuscript. Retrieved from http://xwordgrammar.pbworks.com

Livingston, S. (2010). Working text: X-Word Grammar and writing activities for students. Washington, DC: Gallaudet University Press.

Lantolf, J. (2007). Conceptual knowledge and instructed second language learning: A socio-cultural perspective. In S. Fotos, \& H. Nassaji (Eds.), Form-focused instruction and teacher education: Studies in honour of Rod Ellis (pp. 35-54). Oxford: Oxford University Press.

Larsen-Freeman, D. (2015). Research into practice: Grammar learning and teaching. Language Teaching, 48, 263-280. https://doi.org/10.1017/S0261444814000408

Macaro, E., \& Masterman, L. (2006). Does intensive explicit grammar instruction make all the difference? Language Teaching Research, 10, 297-327. https://doi.org/10.1191/1362168806lr197oa

Noguchi, R. R. (1991). Grammar and the teaching of writing. Urbana, IL: National Council of Teachers of English.

Polio, C., \& Shea, M. (2014). An investigation into current measures of linguistic accuracy in second language writing research. Journal of Second Language Writing, 26, 10-27. http://dx.doi.org/10.1016/j.jslw.2014.09.003

Scheffler, P. (2012). Theories pass. Learners and teachers remain. Applied Linguistics, 33, 603-607. https://doi.org/10.1093/applin/ams062

Sloane, D. E. E. (2009). A sentence is not a complete thought: X-Word Grammar. English Language Teaching, 2, 3-7. https://doi.org/10.5539/elt.v2n2p3

Spada, N., \& Tomita, Y. (2010). Interactions between type of instruction and type of language feature: A meta-analysis. Language Learning, 60, 263-308. https://doi.org/10.1111/j.1467-9922.2010.00562.x

Ur, P. (2016). Grammar practice. In E. Hinkel (Ed.), Teaching English grammar to speakers of other languages (pp. 109-127). New York: Routledge.

Wang, G., \& Wang, S. (2014). Explicit grammar instruction for EFL writing and editing: An exploratory study at a Korean university. Linguistics and Literature Studies, 2, 65-73.

Wolfe-Quintero, K., Inagaki, S., \& Kim, H.-Y. (1998). Second language development in writing: Measures of fluency, accuracy \& complexity. Honolulu, HI: University of Hawai'i, Second Language Teaching and Curriculum Center.

\section{Appendix A}

\section{A Comparison of Traditional Grammar and X-Word Grammar Correction Symbols}

Table A1. Verb tense correction symbols

\begin{tabular}{ll}
\hline $\begin{array}{l}\text { Traditional Grammar Error Correction Key } \\
\text { VT-Wrong Verb Tense }\end{array}$ & $\begin{array}{l}\text { X-Word Grammar Correction Symbols } \\
\text { TIME, V/Xs, V/Xo, V/XD }\end{array}$ \\
\hline VT & TIME \\
$\begin{array}{c}\text { A blue-footed booby was a kind of seabird } \\
\text { VT }\end{array}$ & $\begin{array}{c}\text { A blue-footed booby was a kind of seabird } \\
\text { V/Xs }\end{array}$ \\
that lived on islands in the Pacific Ocean. & that lived on islands in the Pacific Ocean. \\
VT & V/Xo \\
People called it a blue-footed booby because \\
its feet are blue. Its beak is also blue. It
\end{tabular}


VT

is using its long blue beak to catch fish. I

never saw a blue-footed booby. In fact,

VT

VT

I never see any animal that is blue. I had seen

only brown and black-footed animals.
$\mathrm{V} / \mathrm{Xs}$

is using its long blue beak to catch fish. I

never saw a blue-footed booby. In fact, $\mathrm{V} / \mathrm{XD}$

TIME

I never see any animal that is blue. I had seen

only brown and black-footed animals.

Table A2. Aspect/verb form correction symbols

\begin{tabular}{cc}
\hline $\begin{array}{l}\text { Traditional Grammar Error Correction Key } \\
\text { Aspect/Verb Forms Past Participle }\end{array}$ & X-Word Grammar Correction Symbols \\
\hline PP & X V V \\
I have be to Times Square & I have be to Times Square \\
\hline
\end{tabular}

Table A3. Agreement correction symbols

\begin{tabular}{|c|c|}
\hline Traditional Grammar Error Correction Key & X-Word Grammar Correction Symbols \\
\hline Agr - Agreement & $\mathrm{S} \quad \mathrm{X}, \quad \mathrm{S} \mathrm{V} / \mathrm{Xs}, \quad \mathrm{S} \mathrm{V} / \mathrm{Xo}$ \\
\hline Agr & $\mathrm{X}$ \\
\hline Sharks and whales does not belong to the same & Sharks and whales does not belong to the same \\
\hline Agr & $\mathrm{V} / \mathrm{Xo}$ \\
\hline class of animal. They both lives in the ocean, & class of animal. They both lives in the ocean \\
\hline Agr & $\mathrm{S} \quad \mathrm{X}$ \\
\hline but whales is mammals and sharks are fish. & but whales is mammals and sharks are fish. \\
\hline Agr & $\mathrm{S} \quad \mathrm{V} / \mathrm{Xs}$ \\
\hline A killer whale live to 29 years old. & A killer whale live to 29 years old. \\
\hline
\end{tabular}

Table A4. Sentence pattern correction symbols

\begin{tabular}{|c|c|}
\hline Traditional Grammar Error Correction Key & X-Word Grammar Correction Symbols \\
\hline Sentence Pattern Errors (end sentence) & $\mathrm{T}, \mathrm{T},+\mathrm{T}, \mathrm{T}=, \mathrm{FT}, \mathrm{TE}$ \\
\hline My brother is older he works at the mall. & $\mathrm{T}$ \\
\hline \multirow[t]{11}{*}{$=$} & My brother is older he works at the mall. \\
\hline & $\mathrm{T},+$ \\
\hline & It rained. The picnic ended. \\
\hline & $\mathrm{T}$ \\
\hline & Choco began to dance around Bertha and \\
\hline & $=$ \\
\hline & Choco cheered her up. \\
\hline & $\mathrm{T}$ \\
\hline & $\begin{array}{l}\text { When I was on my way. I saw someone yelling } \\
\text { at me. }\end{array}$ \\
\hline & $\mathrm{E}$ \\
\hline & $\begin{array}{l}\text { She started to lose a lot of weight. Because she } \\
\text { refused to eat. }\end{array}$ \\
\hline
\end{tabular}


Note. The Traditional Grammar Error Correction Key is adapted from the college's English language immersion program's error correction key. X-Word Grammar Correction Symbols are from Livingston, 2010, pp. 114-115.

\section{Appendix B}

\section{Readings Used as Essay Prompts at Three Data Points}

September

Hellmich, N. (2011, November 29). Family plays key role in monitoring kids' weight. USA Today, p. 28.

October

Gallegos, D. (2013, September 1). Should you pay a kid for getting good grades? The Wall Street Journal. Retrieved from http://www.wsj.com/articles/SB10001424127887323407104579036931930916274

November

Sperm bank babies: When parents don't get what they want (adapted). (2014, October). The Week. Retrieved from http://theweek.com/print/690/28777/article

\section{Appendix C}

\section{Coding Guidelines (X-Word Terminology in Parentheses)}

General guidelines:

1) Define sentence boundaries by using students' own punctuation which can be commas.

2) Analyze sentence pattern errors before verb errors. Cross out incomprehensible parts of sentences or entire incomprehensible sentences. Cross out these parts on essays being coded for verb construct errors and don't consider them in the analysis for verb errors. Add the number of crossed out words to the $300^{\text {th }}$ word to maintain a 300-word count.

3) Do not analyze quoted or copied language from the readings.

4) Start the analysis at the post-predicate that complement clause in sentences that are introduced with I wish, I think, I believe, the author said, I agree/disagree.

5) If verb constructs and sentence patterns are correct in part of a longer sentence with errors elsewhere, tally those constructs and patterns as correct.

Table C1.

\begin{tabular}{lll}
\hline Verb Error Types & \\
\hline Tense (TIME-now/before, V/Xs, & Missing time & Mostly worker women_not prepare lunch at \\
V/Xo, V/XD) & construct & home
\end{tabular}

Wrong time reference

Subject-verb Agreement

(Number \#--SX, S V/Xs, S V/Xo)
Wrong agreement with auxiliary
Children like to play video games. They spent more time of day ...

[In the article] that third grade boy have a problem but still his mom didn't take him to the doctor

Although the children doesn't care how is the nutritious in his life, and for that they get overweight ... 
Wrong agreement The child is extremely obese and need help... with verb

Everyone knows that kids loves hamburgers

Aspect/Verb Forms (XV matches)

Missing main

It will good and faster verb form

Wrong main verb form

When kids ask for something to eat, they will gave as much as their kids want

Some parents think they don't have the problem [and] maybe the schools have the problems, because those don't putting a stop for the fast food

Table C2.

Sentence Pattern Error Types

Simple sentences (trunks -T)

Missing sentence

I think

is not a good idea take child's away sectors from his parents and living with somebody else

Wrong end

It is not a game,_it is a life. punctuation

Wrong word order

The parents also provide to her kids healthy food

\section{Conjoined sentences $(\mathrm{T},+\mathrm{T}, \mathrm{T}=)$}

Missing comma with coordinating conjunction

Missing coordinating conjunction

Wrong coordinating conjunction

Missing parallel verb

Missing coordinating conjunction with parallel verbs
I agree with her_but I do not agree with moved the child from his/her family

The second aspect with which I disagree with the author is that she has a conscious that she is bribing her kids, she admits it

I think that family can do a lot for a kid with overweight because I used to be an overweight kid when I was younger,-and my friends and parents helping me to control it

She take care her family member, made kids food, shopping for family member and own job

Instead of fried them we can cooked in the grill replace French fries for some vegetables 
Sentences with Subordinators

(FT, TE)

\author{
Missing comma \\ for front \\ subordinator
}

End subordinator not attached to sentence

Wrong use of comma for end subordinator
Maybe if school and other institutions say more information for this problem _ the people search a solution

They can't do that__Cause I think nothing is better than family for the children

Nanci Herllmich said that weight control is a family affair, because the obesity and weight are a big problem for society

\section{Copyrights}

Copyright for this article is retained by the author(s), with first publication rights granted to the journal.

This is an open-access article distributed under the terms and conditions of the Creative Commons Attribution license (http://creativecommons.org/licenses/by/4.0/). 